\title{
Renal sarcoidosis: a rare case
}

\author{
Maria Menezes, ${ }^{1}$ Eunice Patarata ${ }^{2}$
}

${ }^{1}$ Nephrology Department, Centro Hospitalar de Lisboa Central EPE, Lisboa, Portugal ${ }^{2}$ Internal Medicine Functional Unit 7.2, Centro Hospitalar Lisboa Central, Lisboa, Portugal

\section{Correspondence to}

Maria Menezes,

mariamarmenezes@gmail.com

Accepted 21 November 2018

Check for updates

(C) BMJ Publishing Group Limited 2018. No commercial re-use. See rights and permissions. Published by BMJ.

To cite: Menezes $M$ Patarata E. BMJ Case Rep 2018;11:e227023. doi:10.1136/bcr-2018227023

\section{SUMMARY}

Sarcoidosis is a multisystemic granulomatous disease with rare renal involvement. We describe a case of a 45-year-old female patient admitted to the hospital with severe acute kidney injury and uveitis. After clinical investigation, sarcoidosis with renal, hepatic and ocular involvement was diagnosed. Renal biopsy revealed acute granulomatous interstitial nephritis and treatment with systemic corticosteroids was started with marked improvement in renal function.

\section{BACKGROUND}

Sarcoidosis is a multisystemic granulomatous disease of unknown aetiology. It is characterised by the presence of non-caseous granulomas (accumulation of activated T cells CD4+ and macrophages) in several organs. The lung is the most affected organ $(90 \%)$, followed by lymph nodes, skin and eye. ${ }^{1}$ The incidence and prevalence are uncertain. Renal involvement is rare, corresponding to $0.7 \%$ of cases. ${ }^{1}$

Renal involvement of sarcoidosis may present abnormal calcium metabolism, nephrolithiasis and nephrocalcinosis, as well as acute tubulointerstitial nephritis with or without granulomas.

Other rare findings include glomerular disease (cases of membranous nephropathy, IgA nephropathy), tubular dysfunction (proximal or distal renal tubular acidosis and Fanconi syndrome), obstructive uropathy (due to nephrolithiasis, retroperitoneal fibrosis, retroperitoneal lymphadenopathy, bladder, urethra or ureter obstruction by granulomas) and even granulomatous angiitis. ${ }^{2}$

The classical renal lesion consists of non-caseous granulomatous tubulointerstitial nephritis. However, this seldom leads to significant kidney disease. Hypercalcaemia and hypercalciuria are main cause of kidney injury, and nephrocalcinosis is the major cause of chronic kidney disease in sarcoidosis. ${ }^{2}$ However, progression to terminal chronic kidney disease is rare. ${ }^{2}$

This case is utterly interesting because this patient, despite having an altered calcium metabolism did not have nephrocalcinosis and suffered from severe acute kidney injury, making the presentation atypical.

\section{CASE PRESENTATION}

We present a case of a 45-year-old female patient, child caretaker, with a medical history of anaemia of unknown aetiology for about 20 years and smoking habits.
The patient was admitted to the emergency department presenting with nausea, vomiting, non-selective anorexia, blurred vision and diplopia, fever and dry non-productive cough in the previous 48 hours. She denied diarrhoea, urinary complaints or any type of drug intake.

At the emergency department, the physical examination revealed a thin and dehydrated patient, temperature of $37.6^{\circ} \mathrm{C}$ and blood pressure of $131 / 80 \mathrm{~mm} \mathrm{Hg}$.

She was initially observed by an ophthalmologist and diagnosed with anterior bilateral uveitis. Topical ocular corticosteroids and antihistamines were prescribed.

The laboratory investigation revealed the following results: hypochromic microcytic anaemia (haemoglobin $10.7 \mathrm{~g} / \mathrm{L}$ ), acute renal lesion with serum creatinine $7.89 \mathrm{mg} / \mathrm{dL}$ and urea $168 \mathrm{mg} /$ $\mathrm{dL}$, hypercalcaemia (serum calcium $10.4 \mathrm{mg} /$ $\mathrm{dL} / 12.4 \mathrm{mg} / \mathrm{dL}$ corrected for albumin) and phosphorus of $5.2 \mathrm{mg} / \mathrm{dL}$. Liver enzymes were altered (elevated gamma glutamyl transferase $136 \mathrm{U} / \mathrm{L}$ and alkaline phosphatase 296 U/L but normal aspartate aminotransferase $24 \mathrm{U} / \mathrm{L}$ and alanine aminotransferase $20 \mathrm{U} / \mathrm{L}$ ), serum protein electrophoresis showed increased beta 2 and gamma and low albumin $1.9 \mathrm{~g} / \mathrm{dL}$. Low fibrinogen of $0.7 \mathrm{~g} / \mathrm{L}$ and erythrocyte sedimentation rate of $26 \mathrm{~mm} / \mathrm{h}$ were found. Urinalysis revealed proteinuria $(50 \mathrm{mg} / \mathrm{L})$ and no white or red blood cells. Urine culture was negative. Blood gas analysis showed metabolic acidosis (bicarbonate of $15.7 \mathrm{mEq} / \mathrm{L}$ and ionised calcium of $1.49 \mathrm{mmol} / \mathrm{L}$ ).

The remaining evaluation had no changes.

Renal and abdominal ultrasound revealed hepatomegaly $(17 \mathrm{~cm})$, steatosis and kidneys in normal topography, regular contours, normal size (right kidney with $12.7 \mathrm{~cm}$ and left kidney with $12.4 \mathrm{~cm}$ ), preserved corticomedullary differentiation without expansive lesions, excretory dilatation, lithiasis nor perirenal collections. Chest X-ray did not reveal pleuroparenchymal lesions.

The patient was admitted to the Internal Medicine ward and the following diagnostic work-up was done to study the acute kidney injury associated with uveitis and liver involvement. Intravenous hydration with saline solution (sodium chloride $0.9 \%$ ) was started with no improvement in renal function.

\section{INVESTIGATIONS}

Since the patient had multiple organ involvement (kidney, liver and eye), systemic conditions had to be ruled out. Also, blood and urine infectious diseases were excluded (HIV, hepatitis A, B, C and 


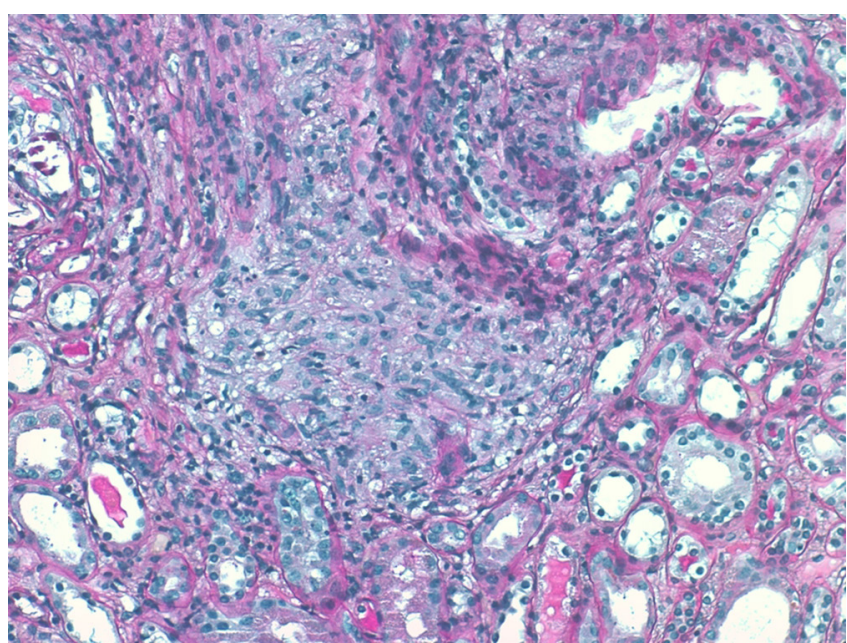

Figure 1 Periodic acid Schiff $\times 200$. Early granuloma formation.

delta, syphilis, Epstein Barr virus and tuberculosis), Epstein Barr virus IgM was negative and IgG was positive (750 U/mL). VDRL (venereal disease research laboratory) test and IGRA (interferon gamma release assay) were also negative.

Drug toxicity was excluded by patient information.

Therefore, hepatitis was ruled out as a possible cause of prerenal insufficiency, regarding the clinical chart of vomiting, dehydration, elevated liver enzymes and liver enlargement. Autoimmune and infiltrative disorders were then investigated.

CT scan confirmed liver enlargement, with no other organ involvement.

Antinuclear antibody was weakly positive, but no other autoantibodies or abnormal serum complement levels were detected. There were no other clinical signs or symptoms. Taking these results into consideration, systemic lupus erythematosus or Sjogren syndrome seemed less likely. ANCA (antineutrophil cytoplasmic antibodies), PR3 (proteinase 3) and MPO (myeloperoxidase) were negative and no respiratory involvement was noted so granulomatosis with polyangiitis was also excluded.

We tried to exclude Hyper IgG4 disease, as the initially $\operatorname{IgG}$ was high $(21.60 \mathrm{~g} / \mathrm{L})$, but the $\operatorname{IgG}$ subclasses $\operatorname{IgG} 1,2,3$ and 4 were within normal range.

As sarcoidosis was suspected, the ACE was measured and found to be high $(495 \mathrm{U} / \mathrm{L})$.

Renal biopsy was performed, which revealed an acute interstitial nephritis with non-caseating granulomas, giant cells, lymphocytic infiltration and rare calcium deposits on light microscopy (figures 1-4).

\section{TREATMENT}

The probable diagnosis of sarcoidosis with renal, ocular and hepatic involvement was assumed and treatment was started with pulses of intravenous methylprednisolone $1000 \mathrm{mg}$ per day for 3 days, followed by prednisolone $40 \mathrm{mg}$ per day.

\section{OUTCOME AND FOLLOW-UP}

The patient showed a sustained improvement of renal function with no need for renal replacement therapy during hospital admission. At discharge (on the 15 th day) serum creatinine was $1.76 \mathrm{mg} / \mathrm{dL}$ with improvement of all the other abnormal analytical parameters.

She was later submitted to respiratory function tests that showed no changes.

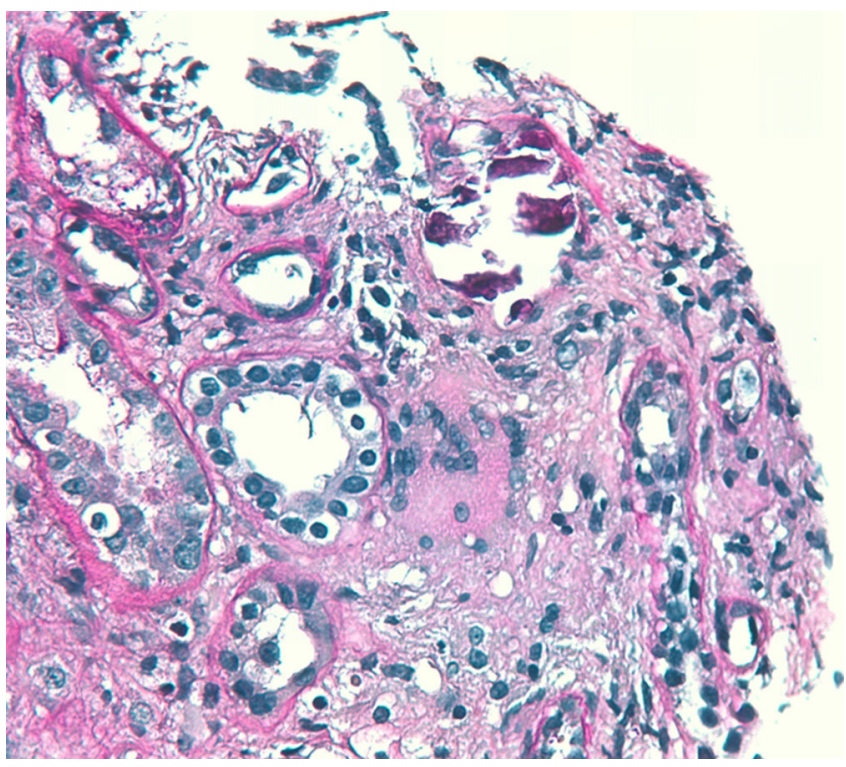

Figure 2 Periodic acid Schiff $\times 400$. Giant multinucleated cell.

The patient completed 4 weeks of the initial corticosteroid dose. One month after discharge, all the analytical parameters (serum creatinine $1 \mathrm{mg} / \mathrm{dL}$, haemoglobin, calcium, liver enzymes and urinalysis) had normalised. A slow weaning of corticosteroids (to prednisolone $10 \mathrm{mg}$ once a day) was tried and, to date, no recurrence was noted.

\section{DISCUSSION}

High serum creatinine, a mild urinary sediment (only with discrete proteinuria), hypercalcaemia, liver involvement, uveitis, an elevated ACE and histologically proven granulomatous acute interstitial nephritis made the diagnosis of sarcoidosis likely.

Nevertheless, other aetiologies of granulomatous interstitial nephritis had to be excluded. In addition to sarcoidosis, the most frequent causes are drugs, infections (such as tuberculosis or syphilis), Wegener's disease and tubulointerstitial nephritis and uveitis (TINU). ${ }^{3-5}$ Our patient denied any prescribed or over the counter medication. Tuberculosis, syphilis and granulomatosis with polyangiitis (Wegener's disease) became unlikely with the clinical results.

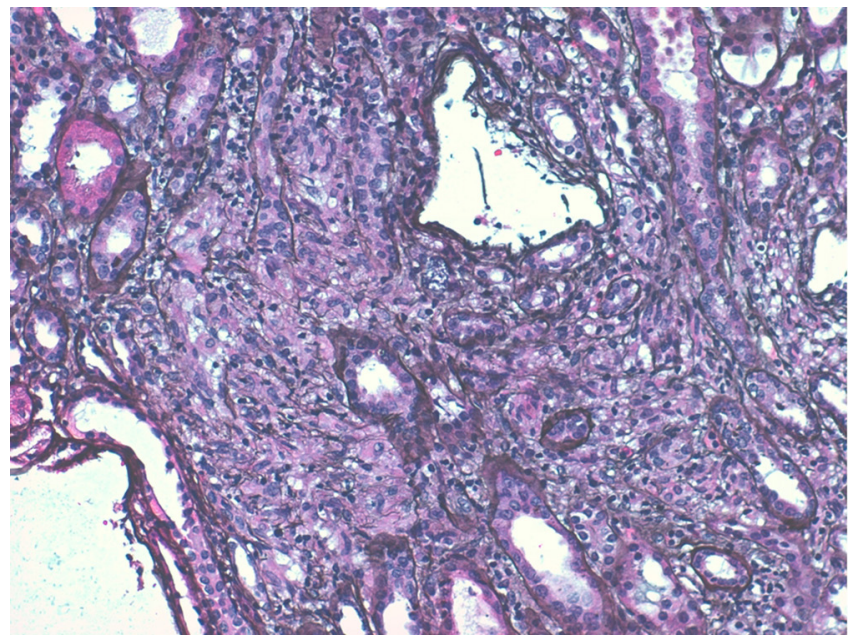

Figure 3 Periodic acid Schiff $\times 400$. Tubulitis and disruption of tubular basement membranes. 


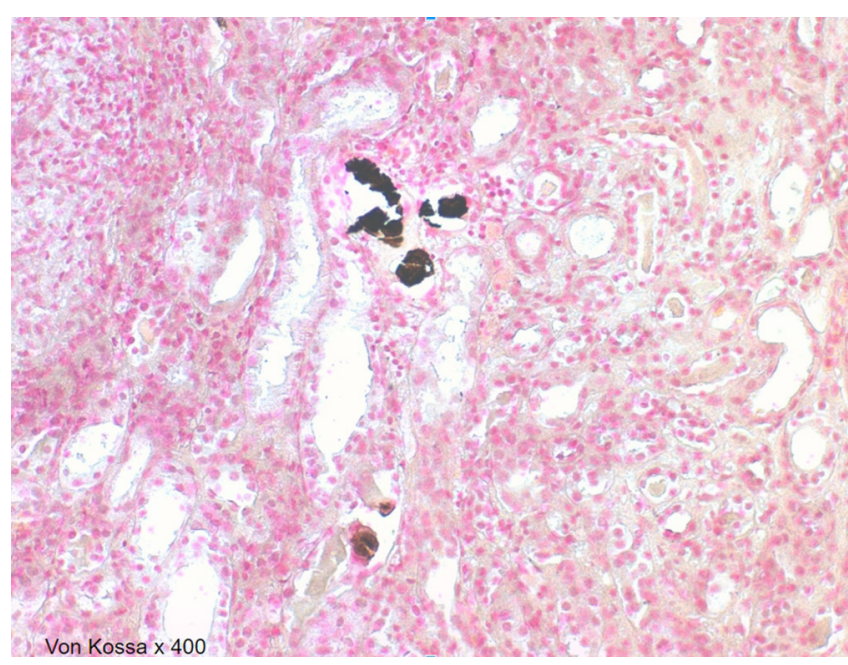

Figure 4 Von Kossa $\times 200$. Tubular calcium deposition.

We cannot safely rule out TINU, as it is common in young women (with a mean age of 15 years), but may occur in adults with TINU. ${ }^{6}$ Elevated liver enzymes and erythrocyte sedimentation rate may also be found in this condition. However, this is an exclusion diagnosis. Hepatomegaly, hypercalcaemia and an elevated ACE were more suggestive of sarcoidosis and therefore, this was the presumptive final diagnosis.

This case is particularly interesting for its atypical presentation: acute renal injury (which is rare in the context of acute granulomatous interstitial nephritis) and the absence of lung involvement (as proven by CT scan and blood gas analysis) that is present in about $90 \%$ of sarcoidosis cases. ${ }^{1}$

Literature concerning patients with renal sarcoidosis is scarce. One study analysed 47 patients with renal sarcoidosis, of which $66 \%$ presented with moderate proteinuria and granulomatous interstitial nephritis. ${ }^{7}$ The same pattern was found in our patient. In contrast, in another study of 27 patients, non-granulomatous interstitial nephritis was more common. ${ }^{8}$ These two studies ${ }^{78}$ showed renal function improvement after oral corticosteroids treatment, as observed in our patient and as recommended by others. ${ }^{9}$

Since this disease has high recurrence, we decided to maintain low dose corticosteroids for 2 years in our patient.

We emphasise that all the investigation performed only allowed us to make the sarcoidosis diagnosis more likely and were in no way exhaustive or exclusive. Unfortunately, no single test confirms this hypothesis and it is still a difficult condition to address.

\section{Learning points}

- Sarcoidosis is a systemic disease with rare renal involvement.

- The primary renal manifestations are nephrolithiasis, nephrocalcinosis and interstitial nephritis with or without granulomas.

- Interstitial nephritis with non-caseous granulomas is the classic histological finding, but rarely causes significant kidney injury.

- Hypercalcaemia and hypercalciuria are usually responsible for relevant kidney disease.

- Renal biopsy findings are only suggestive. Clinical and complementary examinations are essential for the diagnosis.

Acknowledgements We would like to thank Dr Inês Aires for the revision of this article and Dr Mário Góis for supplying the images.

Contributors MM and EP are major contributors in writing and preparing the manuscript.

Funding The authors have not declared a specific grant for this research from any funding agency in the public, commercial or not-for-profit sectors.

Competing interests None declared.

Patient consent for publication Obtained.

Provenance and peer review Not commissioned; externally peer reviewed.

\section{REFERENCES}

1 Baughman RP, Teirstein AS, Judson MA, et al. Clinical characteristics of patients in a case control study of sarcoidosis. Am J Respir Crit Care Med 2001;164:1885-9.

2 Göbel U, Kettritz R, Schneider W, et al. The protean face of renal sarcoidosis. J Am Soc Nephrol 2001;12:616-23.

3 Javaud N, Belenfant X, Stirnemann J, et al. Renal granulomatoses: a retrospective study of 40 cases and review of the literature. Medicine 2007;86:170.

4 Joss N, Morris S, Young B, et al. Granulomatous interstitial nephritis. Clin J Am Soc Nephrol 2007;2:222-30.

5 Shivani S, Carter-Monroe N, Atta M. Granulomatous interstitial nephritis. Clin Kidney 2015;8:516-23.

6 Li C, Su T, Chu R, et al. Tubulointerstitial nephritis with uveitis in Chinese adults. Clin J Am Soc Nephrol 2014;9:21-8.

7 Mahévas M, Lescure FX, Boffa JJ, et al. Renal sarcoidosis: clinical, laboratory, and histologic presentation and outcome in 47 patients. Medicine 2009;88:98.

8 Löffler C, Löffler U, Tuleweit A, et al. Renal sarcoidosis: epidemiological and follow-up data in a cohort of 27 patients. Sarcoidosis Vasc Diffuse Lung Dis 2015;31:306.

9 Hilderson I, Van Laecke S, Wauters A, et al. Treatment of renal sarcoidosis: is there a guideline? Overview of the different treatment options. Nephrol Dial Transplant 2014;29:1841-7.

Copyright 2018 BMJ Publishing Group. All rights reserved. For permission to reuse any of this content visit

https://www.bmj.com/company/products-services/rights-and-licensing/permissions/

BMJ Case Report Fellows may re-use this article for personal use and teaching without any further permission.

Become a Fellow of BMJ Case Reports today and you can:

- Submit as many cases as you like

- Enjoy fast sympathetic peer review and rapid publication of accepted articles

- Access all the published articles

- Re-use any of the published material for personal use and teaching without further permission

For information on Institutional Fellowships contact consortiasales@bmjgroup.com

Visit casereports.bmj.com for more articles like this and to become a Fellow 